\title{
Healthcare workers' heterogeneous mental-health responses to prolonging Covid-19 pandemic: A full year of monthly follow up in Finland
}

Tom Rosenström, ${ }^{1,}{ }^{*}$ Katinka Tuisku, ${ }^{2}$ Jaana Suvisaari, ${ }^{3}$ Eero Pukkala, ${ }^{4}$ Kristiina Junttila, ${ }^{5}$ Henna Haravuori, ${ }^{3}$ Marko Elovainio,1,6 Toni Haapa,,5 Pekka Jylhä,, ${ }^{2}$ Tanja Laukkala²

${ }^{1}$ Department of Psychology and Logopedics, Faculty of Medicine, University of Helsinki, 00014 Helsinki, Finland

2 Department of Psychiatry, University of Helsinki and Acute Psychiatry and Consultations, HUS Helsinki University Hospital, 00029 Helsinki, Finland

3 Finnish Institute for Health and Welfare, Mental Health Team, 00271 Helsinki, Finland

4 Faculty of Social Sciences, Tampere University, 33100 Tampere, Finland

${ }^{5}$ Nursing Research Center, HUS Helsinki University Hospital and University of Helsinki, 00029

Helsinki, Finland

6 Finnish Institute for Health and Welfare, Health Services Research, 00271 Helsinki, Finland

*Correspondence: tom.rosenstrom@helsinki.fi

Orcid IDs:

TR: https://orcid.org/0000-0001-8277-3776

TL: https://orcid.org/0000-0002-7361-0964

TH: https://orcid.org/0000-0002-8783-2998

KJ: https://orcid.org/0000-0002-3541-601X

HH: https://orcid.org/0000-0002-4080-7779 


\section{Abstract}

Purpose: To investigate changes in healthcare workers' mental-health under prolonging Covid-19 pandemic conditions.

Methods: A monthly survey over a full year was conducted for employees of the HUS Helsinki University Hospital ( $n=4804$ ) between 4th June 2020 to 28th May 2021. Pandemic-related potentially traumatic events (PTEs), work characteristics (e.g., contact to Covid-19 patients), and other covariates were used to predict Mental Health Index-5 (MHI-5) and Insomnia Severity Index (ISI) in generalized multilevel and latent-class mixed model regressions.

Results: Local Covid-19 log-incidence (odds ratio, $\mathrm{OR}=1.21$, with $95 \% \mathrm{CI}=1.10-1.60$ ), directly caring for Covid-19 patients (OR $=1.33, \mathrm{CI}=1.10-1.60)$ and PTEs $(\mathrm{OR}=4.57, \mathrm{CI}=3.85-5.43$ ) were all independently associated with low mental health, when (additionally) adjusting for age, sex, profession, and calendar time (a $5^{\text {th }}$ degree polynomial expansion). Independence from time suggests effects of incidence change in time. Effects of local Covid-19 incidence on sleep were fully dependent on time. Latent mental-health trajectories were characterized by a large class of "stable mental health" and minority classes for "early shock, improving" and "early resilience, deteriorating" mental health. The minority classes, especially "early shock, improving", were more likely to live alone and be exposed to PTEs than others.

Conclusion: Healthcare workers face increasingly heterogeneous mental-health challenges as the Covid-19 pandemic prolongs. Adversity and mental ill-being may accumulate in some employees. More research is needed on the factors affecting employees' resilience to the prolonging pandemic. Living arrangements may play a role.

Keywords (4-6): SARS-CoV-2, psychological distress, sleep problems, insomnia, latent-class mixed models, traumatic events 


\section{Introduction}

Covid-19 pandemic represents a global threat not only to physical but also to mental health. In the general population, that threat has manifested in relatively high rates of symptoms of anxiety, depression, post-traumatic stress disorder, psychological distress, and stress [1, 2]. Evidence on exact prevalence is still mixed. For example, Canadian meta-analysts estimated a depression prevalence of 15.97\% (95\% CI: 13.24-19.13\%) during first year of pandemic, whereas Chinese meta-analysts estimated a prevalence of 31.5\% (95\% CI: $24.2-39.2 \%)$ on mostly the same period $[3,4]$. Nevertheless, both the meta-analyses found that healthcare workers had higher rates of insomnia compared to other population. Transient insomnia is an early marker of stress that represents a common response to environmental and psychological challenges. Prolonged and frequent insomnia symptoms, however, predict higher rates of sickness absence, mental illness, and disability pensions $[5,6]$.

Many healthcare workers may have experienced a double burden of stress from Covid-19 compared to the general population given their (at least) comparable risk to own health and the additional work stress deriving from high prevalence of patients with infectious diseases [7]. It has been shown that workload due to infections-related hospital ward overcrowding may lead to depression and sickness absence in healthcare staff [8-10]. Several targeted meta-analyses suggest that healthcare workers, especially female nursing staff with close contact to Covid-19 patients, may be at higher risk of psychiatric symptoms during the Covid-19 pandemic compared to other professionals [2, 11-13, but see 3$]$. 
In the general population, a more nuanced picture on mental-health impact of Covid-19 is beginning to emerge. Various mental-health trajectories during Covid-19 pandemic have been observed, depending on factors like local lockdowns, financial difficulties, pre-existing conditions, and contracting the infection $[14,15]$. There are inevitable differences in individual and social resources to cope with stress from Covid-19, and heterogeneity in psychosocial and physical work environments. Thus, one might expect latent heterogeneity also in the healthcare workers' response to prolonged Covid-19 pandemic over time. This paper examines factors affecting healthcare workers' mental-health trajectories over time during the Covid-19 pandemic using monthly personnel follow up across a full year of pandemic conditions.

The entirety of the personnel of the HUS Helsinki University Hospital $(n=25,494)$ was invited to participate in a baseline online survey during a difficult early phase of Covid-19 pandemic in June 2020, with 4804 employees (19\%) answering [16]. The respondents of the baseline survey were sent monthly follow-up surveys. Until a half-year follow up, we found that temporal variations in local Covid-19 incidence rates correlated with the personnel's psychological distress, with frontline work and pandemic-related potentially traumatic events (PTE) further increasing the risk of low mental health [17]. Nursing staff were more likely to be at frontline, but the half-year follow-up data did not allow determining whether this explained the greater risk of low mental health among nursing staff. Further, as vaccination coverage has increased and the pandemic prolonged, one might anticipate less clear a link between local Covid-19 incidence and employees' psychological distress and increasing heterogeneity in how the employees cope with the pandemic in their private lives. Now having a full year of monthly follow-up data on these employees, we are in a position to better disentangle psychological risk 
factors for coping with pandemic work, including latent heterogeneity in the personnel's mentalhealth response to the prolonging pandemic.

We aimed to investigate healthcare workers' mental-health under prolonging Covid-19 pandemic conditions. We followed mental-health consequences of Covid-19 pandemic for the HUS hospital personnel over one year, modeling risk factors of and latent heterogeneity in psychological distress. Examining latent population strata in healthcare workers' reactions to prolonging pandemic may provide important information for employers and occupational health service providers. On one hand, evidence for such strata exists from the general population [14, 15]. On the other hand, employees by definition lack some of the obvious correlates of population stratification, such as unemployment [15], making risk stratification amongst healthcare workers a novel question.

\section{Methods}

\section{Study population and measures}

This study was approved by the HUS Ethical Committee and permission to conduct the study was obtained from the HUS Joint Resources. Since our initial publication and the half-year follow up $[16,17]$, we have received follow-up data spanning an entire year. The available answers span the period from 4th June 2020 to 28th May 2021, totaling 358 days. The initial sample $(\mathrm{n}=4804)$ contained nursing staff (62\%), medical doctors (9\%), special personnel such as psychologists and social workers (8\%), and other non-healthcare personnel (21\%), and overall predominantly (88\%) females [16]. Average age was 44 years (s.d. 11 years), with a broad range of educational backgrounds: Bachelor's degree equivalent was the most common highest educational level (55\%), but also many doctoral-degree equivalents (10\%) were in the sample (see [16] for a full 
breakdown). The electronic survey consists of few open questions, questions on pandemic workrelated potentially traumatic events and symptom-rating scales, including Mental Health Index (MHI-5) and Insomnia Severity Index (ISI). We defined low mental health by MHI-5 scores 52 or below [18-20], whereas ISI scores 15 or over were used to indicate presence of sleep problems [21]. Although a bit over half the sample was lost to attrition in 1st follow-up survey, altogether $82 \%$ returned to at least some of the 11 follow-up surveys (Supplementary Table S1 shows the number of respondents and other data by each survey wave).

\section{Other data}

Weekly Covid-19 incidence rates in Uusimaa region that the HUS hospital district serves were drawn from an open data repository of the Finnish Institute of Health and Welfare (https://sampo.thl.fi/pivot/prod/en/epirapo/covid19case/).

\section{Statistics}

We drew boxplots and local regression lines to illustrate the data to the reader. We then modeled the associations between risk factors and outcomes with multilevel (mixed-effects) logistic regression models, using a random intercept to model employee-specific risks that are constant over repeat measurements $[22,23]$. All data points (survey answers at given time) with all model-required variables available were used in modeling despite the employee lacking some survey waves. The effects of time were modeled with polynomials of standardized calendar dates and/or with time-specific local Covid-19 log-incidence per week. More specifically, we transformed the incidence rate defined as weekly number of new cases $r$ to $\log (r+1)$ for regression modeling to linearize the generally exponential growth rate of infection transmission. We strived to first exhaust the effects of simple calendar time by adding polynomials of time until 
a non-significant higher order polynomial was encountered. Other studied covariates were then adjusted for the time polynomials, age, and sex, plus sequentially to each other.

We modeled latent heterogeneity in mental health trajectories using latent class mixed models [24]. We first selected a degree for polynomial expansion that maximized Bayesian information criterion for a single-class model. In a previous research on the general population of the UK [14], even such complexity-adjusted statistical fit criteria tended to suggest very many latent classes, and therefore in that study the number of classes was cut from the first major drop in the relative Bayesian information criterion values instead of seeking for an absolute minimum. We also looked at that criterion and found that the ensuing number of classes was also favored by integrated complete likelihood criterion that combines Bayesian information criterion with entropy-based classification accuracy $[25,26]$. In our case, only these criteria maintained reasonably dissociable latent classes $(<30 \%$ posterior confusion probability for class membership in each class; see supplementary material for additional details) and were thus used. We used in the analyses R version 4.0.2 (2020-06-22) and lme4 (version 1.1-23) and the lcmm (version 1.9.3) packages $[23,24]$.

\section{Results}

\section{Sample characteristics}

The survey waves approximately reflect the time the participants answered the online questionnaire, with some variation within the waves (Figure 1a). Besides large variation between individuals (Figure 1b), a mean-level pattern across the survey waves was evident for mental health (Figure 1c), such that it roughly inverse-tracked the local progression of Covid-19 case rate (Figure 1d). On average, the mental health index was low right after the first peak of the 
epidemic, increased during the subsequent relatively serene phase of the epidemic, and deteriorated again with re-emergence of infections (Figure 1c-d).

\section{Point-wise correlates of low mental health and sleep problems during a full year of pandemic} conditions

Table 1 shows a series of multilevel models predicting low mental health (MHI- 5 score $\leq 52)$. In the Model 1, we observed that being a member of the nursing staff and having the Covid-19 contact independently increased the risk of low mental health (an interaction of being a nurse and having a contact was non-significant, however; $p=0.105$ ). The differential mental-health risk between professions did not withstand adjusting for potentially traumatic events (Model 2, Table 1), although nurses on average were not statistically significantly more prone to such events (OR $=1.82,95 \% \mathrm{CI}=0.84-3.99$, when adjusting age, sex, and employee-specific random intercept). The effects of national Covid-19 incidence on mental health of the personnel was a partly independent risk factor from the polynomial expansion of calendar time (Models 3 and 4 in Table 1). This suggests either temporally evolving mental-health impact of Covid-19 incidence or the emergence of other time-dependent processes affecting mental health than Covid-19 incidence.

To test whether linear time interacted with mental-health impact of Covid-19 incidence, we additionally introduced main effect of standardized calendar time and its interaction with incidence to Model 3 of Table 1 (Model 5; note: Model 4 did not converge with the interaction effect). This increased the OR of log-incidence from $1.26(95 \% \mathrm{CI} 1.21-1.32)$ to $1.54(\mathrm{CI}=1.42-$ 1.68), with the effect of log-incidence increasing by time (interaction's $\mathrm{OR}=1.10, \mathrm{CI}=1.03-1.18$ ) and with calendar time itself having a risk-reducing effect $(\mathrm{OR}=0.4, \mathrm{CI}=0.25-0.64)$. Given these and other evidence for temporally evolving mental-health effect of local incidence, we turned to 
latent-class modeling (in below sub-section) to detect possible other time-dependent heterogeneity in mental-health trajectories during pandemic.

Before that, sleep problems were studied as an outcome distinct to low mental health. A Covid-19 contact also increased risk of sleep problems, whereas being a nurse did not (Model 1, Table 2). Relative to results on low mental health, sleep problems were more strongly associated with provision of direct care to Covid-19 patients and less strongly with PTEs and local Covid-19 incidence (Table 2). However, qualitatively the findings for sleep problems were rather similar to those for low mental health (Table 2 vs. 1). Temporally stable betweenindividual differences contributed more to risk of sleep problems than to risk of low mental health (Table 2 vs. 1 random-effect variance).

\section{Latent heterogeneity in mental-health trajectories during a prolonged pandemic}

We estimated three latent classes to underlie the observed trajectories of MHI-5 scores in the sample (see Methods and supplementary material). As the mental-health score was heavily leftskewed with a clear upper limit (Figure 2a), we linked it with a latent normal variate using a rescaled cumulative Beta distribution [24]. Figure $2 \mathrm{~b}$ shows the average latent-class trajectories in these latent normal-variate units, with higher values implying higher mental health. All the classes showed a rapid initial improvement of mental health after the shock from the first peak epidemic, but otherwise the trajectories behaved differently.

The employees in the third (reference) latent class (62\% of all employees) showed relatively stable trajectories with less fluctuation compared to the other classes (Figure $2 \mathrm{~b}$, solid line; we name this class "stable mental health"). The employees in the second latent class (14\%) suffered the most from the initial shock but adjusted the best with the prolonged pandemic 
conditions (Figure 2b, dashed line; "early shock, improving"). The employees in the first latent class (24\%) seemed to suffer less than the others from the initial shock but more than the others from prolonged pandemic conditions (Figure 2b, dotted line; "early resilience, deteriorating").

Age, sex, delivering direct Covid-19 care, nursing profession, or Covid-19 incidence were not associated with membership of these latent classes, however-only PTEs were. Some of the specific PTEs we assessed pertained work life, whereas others pertained infection transmission risk in private life (see Table 3 covariate descriptions). As risk of transmission ought to vary by living arrangements, we strived to unpack the meaning of the observed three latent classes by regressing them on both the specific PTEs and living arrangement (living alone) within the original latent-class mixed model (joint estimation). The employees in the class "early shock, improving" (class 2) were more likely to live alone than others and more likely to have experienced a PTE compared to others (Table 3; see supplementary information for the full joint set of model parameters).

In a supplementary analysis, we modified the Model 2 of Table 1 to show that living alone predicted low mental health after adjusting for PTEs and that the influence of PTEs on mental health declined over time. The second latent class could have captured some of these effects. Accordingly, supplementary point estimates (Table S4 for full breakdown) indicated that $92 \%$ of employees in the class "early shock, improving" experienced a PTE at baseline and 36\% in the last follow-up. In contrast, $6 \%$ of employees in the reference class "stable mental health" experienced a PTE in baseline and 7\% in the last follow up. Across all the waves, the latent classes 1 ("early resilience, deteriorating"), 2 ("early shock, improving"), and 3 ("stable mental health") on average had 25.9\%, 52.5\%, and 6.2\% employees with potentially traumatic events 
(PTE), respectively, and 28.2\%, 33.0\%, and 16.9\% employees who lived alone. Occasionally, the latent groups had very large prevalence differences, which explains the high OR-values in Table 3 (e.g., 79.2\% vs. 0.8\% prevalence for PTE2, “own or close one's risk of severe illness provoked severe anxiety", in classes 2 vs. 3).

\section{Discussion}

When we in June 2020 first initiated follow up of Finnish hospital employees in HUS region [16], $43.4 \%$ of the employees directly involved in Covid-19 pandemic patient care reported potentially traumatic Covid-19-related events-a proportion much greater than for personnel not in direct Covid-19 patient care (21.8\%). While some indexes derived from social media have suggested a return to a new normal after first pandemic wave, with associated decline in anxiety [27], our follow up surveys half a year later revealed that also the later epidemic waves hit hard on the employee and population mental well-being in Finland [17]. As elsewhere, we observed frontline nursing staff to be at higher risk than others, but in the half-year data, could not dissociate the effect of frontline work from the effect of being a member of nursing staff [17]. In this one-year follow up of the same hospital employees, we began to see an independent effect of frontline work. This longer follow up also revealed a dissociation of Covid-19 incidence and calendar time as risk factors for low mental, but not as risk factors for insomnia. PTEs remained an important risk factor for low mental health but their impact declined in time, whereas impact of Covid-19 incidence increased in time. Mental health over the prolonging pandemic period reflected three latent classes, differentially associated with PTEs and living conditions.

We examined both low mental health and sleep problems as outcomes of pandemic working conditions. Sleep problems are a common first psychiatric symptom in prolonged stress and reciprocal relations between insomnia and perceived work stress have been previously 
established [28]. More generally, unmanageable stress may lead to insomnia via hyper-arousal, whereas fragmented sleep may exacerbate daytime distress via emotional dysregulation [29]. The association between Covid-19-related stress and sleep disturbance among health care personnel and general population has been shown in earlier studies [30, 31]. Here, we found both similarities and differences for sleep problems and low mental health in the hospital employees. While both treating Covid-19 patients and experiencing PTEs were risk factors for both low mental health and sleep problems, treating Covid-19 patients had an effect of a comparable magnitude on these outcomes whereas PTEs had almost two times higher effect on low mental health compared to sleep problems. Furthermore, Covid-19 incidence had an independent effect on low mental health even after adjusting for calendar time, whereas it did not have such an effect on sleep problems. That is, novel kinds of incidence effects on low mental health, but not on sleep, emerged over time. Earlier Covid-19 studies have highlighted sleep problems [3, 4] and moral injuries in healthcare workers [7], but we may already begin to see diffuse downstream mental-health effects of these early indicators of prolonged stress in this one-year follow up. As the pandemic prolongs, transient stress reactions and accumulating adversity may increasingly predict differential health outcomes.

Arguably, the greatest health impacts of the pandemic in Finland thus far concentrated on its early phase around the second quarter of the year 2020, when many inadequately isolated elderlies died with infection-related complications. Also, the pure novelty of the dangerous situation may have evoked anxiety in the population at that time. Accordingly, we observed the greatest rates of reported PTEs amongst the personnel during the first survey waves, and PTEs had greatest effect on mental health at that time (Supplementary Tables S1 and S2). We also found evidence for existence of a sub-group of employees who experienced great psychological 
distress during the first survey waves but recovered and stayed at the higher mental-health level thereafter. Members of this latent sub-group were more likely to live alone compared to other employees, and more likely to have experienced a PTE. This minority group thus appeared rattled but not affected in the long term in what comes to mental health. The majority of the employees followed a steadier mental-health trajectory throughout the pandemic, but another minority sub-group appeared to be relatively well at the beginning but suffered from the prolonging pandemic. This sub-group may contain employees experiencing stronger doubleburden with a situation of a family struggling to cope with the pandemic conditions of the surrounding society. They may represent a group coping well with acute stress and emergency work re-arrangements, but gradually decompensating with the prolonged extra workload and responsibility. Increased quantitative and qualitative personnel demands, with shattered work teams, abrupt transfers of personnel, restricted vacations, challenges to learn, adapt and teach new practices may pose long term stressors with deficient options for recovery.

Further research on how employees' families have been affected by the pandemic seem increasingly important as the pandemic prolongs. Work efficacy of employees might significantly suffer from having to worry about how to manage financially or otherwise if a spouse has lost a job or the usual day-care arrangements have been compromised. Financial difficulties have emerged as a risk factor of mental-health problems during Covid-19 pandemic in previous studies of the UK general population $[14,15]$. In our study, living alone was a risk factor for low mental health but also predicted membership in the latent class where mental health improved from the initial shock. This pattern may pertain to the dual role of loneliness as a factor weakening general mental-health resilience on one hand [32-34] and as an obvious factor 
protecting from anxiety-provoking viral transmission risk and from risk of household rearrangements related to Covid-19.

In our previous half-year follow-up paper [17], the data restricted our ability to adjust the exposure of direct Covid-19-care for belonging to nursing staff because this group had most of the early Covid-19 patient contacts. In the Model 1 of this longer follow up, we observed that being a member of nursing staff and having the Covid-19 contact independently increased the risk of low mental health. In other words, profession may be a protective factor against Covid-19 contacts but not against the consequences of a contact. A Covid-19 contact also increased risk of sleep problems, whereas being a member of nursing staff did not. The differential mental-health risk between professions did not withstand adjusting for potentially traumatic events, however (Model 2, Table 2), although nursing staff on average was not statistically significantly more prone to such events $(\mathrm{OR}=1.82,95 \% \mathrm{CI}=0.84-3.99$, when adjusting age, sex, and employeespecific random intercept).

Findings of this study should be interpreted in the light of its limitations. First, the response rate to the baseline survey was relatively low (19\%), which could pertain to difficulties in reaching employees with an electronic survey in the middle of pandemic work. Our relatively dense (monthly) follow-up sampling may have been a compensating strength, as many who did not fill in the first follow-up survey nevertheless did have a chance to participate in some of the later surveys ( $47 \%$ re-participated to the first follow up but $82 \%$ to at least one of the follow ups). Second, we had limited data on socioeconomic background, living conditions, and other individual differences (e.g., personality) that may affect how the employees cope with pandemic working conditions. However, one would expect many of such factors to change slowly relative to 
stressors during a year of pandemic conditions, and therefore our densely sampling surveys

likely provide a good overall picture on how the respondents and the employee-population they represent responded to the investigated mental-health risk factors.

In conclusion, exposure to direct pandemic patient work, potentially traumatic events related to it, and local burden of transmission all influenced employee mental well-being throughout a year of Covid-19 pandemic conditions. Despite such robust effects, the year-long prolongation of pandemic conditions gave rise to latent heterogeneity in the employees' mentalhealth response to the pandemic. Besides controlling of the established exposures, following how individual employees and their families cope with the pandemic is increasingly important if we are unable to rid ourselves from Covid-19 entirely.

\section{Funding}

TR was supported by the Academy of Finland (grant numbers 334057 and 335901) and HUS Helsinki University Hospital.

\section{Competing interests}

The authors have no relevant financial or non-financial interests to disclose.

\section{Institutional review board statement}

The study was conducted according to the guidelines of the Declaration of Helsinki, and approved by the Ethics Committee of the Helsinki University Hospital (protocol code HUS/1488/2020 6 May 2020). Informed consent was obtained from all subjects involved in the study. 


\section{Data Availability Statement}

The data are not publicly available due to privacy restrictions. Regarding access, please contact the principal investigator Tanja Laukkala (Tanja.Laukkala@hus.fi).

\section{References}

1. Xiong J, Lipsitz O, Nasri F, et al (2020) Impact of COVID-19 pandemic on mental health in the general population: A systematic review. J Affect Disord 277:55-64.

https://doi.org/10.1016/j.jad.2020.08.001

2. Vindegaard N, Benros ME (2020) COVID-19 pandemic and mental health consequences: Systematic review of the current evidence. Brain Behav Immun 89:531-542. https://doi.org/10.1016/j.bbi.2020.05.048

3. Cénat JM, Blais-Rochette C, Kokou-Kpolou CK, et al (2021) Prevalence of symptoms of depression, anxiety, insomnia, posttraumatic stress disorder, and psychological distress among populations affected by the COVID-19 pandemic: A systematic review and metaanalysis. Psychiatry Res 295:113599. https://doi.org/10.1016/j.psychres.2020.113599

4. Wu T, Jia X, Shi H, et al (2021) Prevalence of mental health problems during the COVID-19 pandemic: A systematic review and meta-analysis. J Affect Disord 281:91-98. https://doi.org/10.1016/j.jad.2020.11.117

5. Lallukka T, Haaramo P, Lahelma E, Rahkonen O (2011) Sleep problems and disability retirement: a register-based follow-up study. Am J Epidemiol 173:871-881.

https://doi.org/10.1093/aje/kwq462

6. Lallukka T, Kaikkonen R, Härkänen T, et al (2014) Sleep and sickness absence: a nationally representative register-based follow-up study. Sleep 37:1413-1425.

https://doi.org/10.5665/sleep.3986

7. Mantri S, Song YK, Lawson JM, et al (2021) Moral injury and burnout in health care professionals during the COVID-19 pandemic. J Nerv Ment Dis 209:720-726. https://doi.org/10.1097/NMD.0000000000001367

8. Virtanen M, Terho K, Oksanen T, et al (2011) Patients with infectious diseases, overcrowding, and health in hospital staff. Arch Intern Med 171:1296-1298.

https://doi.org/10.1001/archinternmed.2011.313

9. Virtanen M, Batty GD, Pentti J, et al (2010) Patient overcrowding in hospital wards as a predictor of diagnosis-specific mental disorders among staff: a 2-year prospective cohort study. J Clin Psychiatry 71:1308-1312. https://doi.org/10.4088/JCP.09m05238blu 
10. Kivimäki M, Vahtera J, Kawachi I, et al (2010) Psychosocial work environment as a risk factor for absence with a psychiatric diagnosis: an instrumental-variables analysis. Am J Epidemiol 172:167-172. https://doi.org/10.1093/aje/kwq094

11. De Kock JH, Latham HA, Leslie SJ, et al (2021) A rapid review of the impact of COVID-19 on the mental health of healthcare workers: implications for supporting psychological wellbeing. BMC Public Health 21:104. https://doi.org/10.1186/s12889-020-10070-3

12. da Silva Neto RM, Benjamim CJR, de Medeiros Carvalho PM, Neto MLR (2021) Psychological effects caused by the COVID-19 pandemic in health professionals: A systematic review with meta-analysis. Prog Neuropsychopharmacol Biol Psychiatry 104:110062. https://doi.org/10.1016/j.pnpbp.2020.110062

13. Moitra M, Rahman M, Collins PY, et al (2021) Mental health consequences for healthcare workers during the COVID-19 pandemic: A scoping review to draw lessons for LMICs. Front Psychiatry 12:602614. https://doi.org/10.3389/fpsyt.2021.602614

14. Pierce M, McManus S, Hope H, et al (2021) Mental health responses to the COVID-19 pandemic: a latent class trajectory analysis using longitudinal UK data. Lancet Psychiatry 8:610-619. https://doi.org/10.1016/S2215-0366(21)00151-6

15. Chandola T, Kumari M, Booker CL, Benzeval M (2020) The mental health impact of COVID-19 and lockdown-related stressors among adults in the UK. Psychol Med Epub ahead of print:110. https://doi.org/10.1017/S0033291720005048

16. Haravuori H, Junttila K, Haapa T, et al (2020) Personnel well-being in the Helsinki University Hospital during the COVID-19 pandemic-A prospective cohort study. Int J Environ Res Public Health 17:E7905. https://doi.org/10.3390/ijerph17217905

17. Laukkala T, Suvisaari J, Rosenström T, et al (2021) COVID-19 Pandemic and Helsinki University Hospital Personnel Psychological Well-Being: Six-Month Follow-Up Results. International Journal of Environmental Research and Public Health 18:2524. https://doi.org/10.3390/ijerph18052524

18. Rumpf HJ, Meyer C, Hapke U, John U (2001) Screening for mental health: validity of the MHI-5 using DSM-IV Axis I psychiatric disorders as gold standard. Psychiatry Res 105:243-253. https://doi.org/10.1016/s0165-1781(01)00329-8

19. Cuijpers P, Smits N, Donker T, et al (2009) Screening for mood and anxiety disorders with the five-item, the three-item, and the two-item Mental Health Inventory. Psychiatry Res 168:250255. https://doi.org/10.1016/j.psychres.2008.05.012

20. Elovainio M, Hakulinen C, Pulkki-Råback L, et al (2020) General Health Questionnaire (GHQ12), Beck Depression Inventory (BDI-6), and Mental Health Index (MHI-5): psychometric and predictive properties in a Finnish population-based sample. Psychiatry Res 289:112973. https://doi.org/10.1016/j.psychres.2020.112973 
21. Morin CM, Belleville G, Bélanger L, Ivers H (2011) The Insomnia Severity Index: psychometric indicators to detect insomnia cases and evaluate treatment response. Sleep 34:601-608. https://doi.org/10.1093/sleep/34.5.601

22. Gelman A, Hill J (2007) Data Analysis Using Regression and Multilevel/Hierarchical Models. Cambridge University Press, New York

23. Bates D, Mächler M, Bolker B, Walker S (2015) Fitting linear mixed-effects models using lme4. Journal of Statistical Software 67:1-48. https://doi.org/10.18637/jss.v067.i01

24. Proust-Lima C, Philipps V, Liquet B (2017) Estimation of extended mixed models using latent classes and latent processes: The R package lcmm. J Stat Softw 78:1-56.

https://doi.org/10.18637/jss.v078.i02

25. Biernacki C, Celeux G, Govaert G (2000) Assessing a mixture model for clustering with the integrated completed likelihood. IEEE Trans Pattern Anal Mach Intell 22:719-725. https://doi.org/10.1109/34.865189

26. van der Nest G, Lima Passos V, Candel MJJM, van Breukelen GJP (2020) An overview of mixture modelling for latent evolutions in longitudinal data: Modelling approaches, fit statistics and software. Adv Life Course Res 43:100323.

https://doi.org/10.1016/j.alcr.2019.100323

27. Saha K, Torous J, Caine ED, Choudhury MD (2020) Psychosocial effects of the COVID-19 pandemic: Large-scale quasi-experimental study on social media. J Med Internet Res 22:e22600. https://doi.org/10.2196/22600

28. Garefelt J, Platts LG, Hyde M, et al (2020) Reciprocal relations between work stress and insomnia symptoms: A prospective study. J Sleep Res 29:e12949.

https://doi.org/10.1111/jsr.12949

29. Kalmbach DA, Cuamatzi-Castelan AS, Tonnu CV, et al (2018) Hyperarousal and sleep reactivity in insomnia: current insights. Nat Sci Sleep 10:193-201. https://doi.org/10.2147/NSS.S138823

30. Wang S, Xie L, Xu Y, et al (2020) Sleep disturbances among medical workers during the outbreak of COVID-2019. Occupational Medicine 70:364-369.

https://doi.org/10.1093/occmed/kqaa074

31. Casagrande M, Favieri F, Tambelli R, Forte G (2020) The enemy who sealed the world: effects quarantine due to the COVID-19 on sleep quality, anxiety, and psychological distress in the Italian population. Sleep Med 75:12-20. https://doi.org/10.1016/j.sleep.2020.05.011

32. Rook KS (1984) Research on social support, loneliness, and social isolation: Toward an integration. Rev Pers Soc Psychol 5:239-264 
33. Elovainio M, Hakulinen C, Pulkki-Råback L, et al (2017) Contribution of risk factors to excess mortality in isolated and lonely individuals: an analysis of data from the UK Biobank cohort study. Lancet Public Health 2:e260-e266. https://doi.org/10.1016/S2468-2667(17)30075-0

34. MacDonald G, Leary MR (2005) Why does social exclusion hurt? The relationship between social and physical pain. Psychol Bull 131:202-223. https://doi.org/10.1037/00332909.131.2.202 


\section{Tables}

Table 1: Multilevel models predicting low mental health.

\begin{tabular}{|c|c|c|c|c|c|c|c|c|c|c|}
\hline \multirow[b]{2}{*}{ Fixed effects } & \multicolumn{2}{|c|}{$\begin{array}{c}\text { Model 1 } \\
\left(\mathrm{N}_{\text {obs }}=22,300 ;\right. \\
\left.\mathrm{N}_{\text {per }}=4,400\right)\end{array}$} & \multicolumn{2}{|c|}{$\begin{array}{c}\text { Model 2 } \\
\left(\mathrm{N}_{\text {obs }}=21,670 ;\right. \\
\left.\mathrm{N}_{\text {per }}=4,366\right)\end{array}$} & \multicolumn{2}{|c|}{$\begin{array}{c}\text { Model 3 } \\
\left(\mathrm{N}_{\text {obs }}=21,670 ;\right. \\
\left.\mathrm{N}_{\text {per }}=4,366\right)\end{array}$} & \multicolumn{2}{|c|}{$\begin{array}{c}\text { Model 4 } \\
\left(\mathrm{N}_{\text {obs }}=21,670 ;\right. \\
\left.\mathrm{N}_{\text {per }}=4,366\right)\end{array}$} & \multicolumn{2}{|c|}{$\begin{array}{c}\text { Model 5 } \\
\left(\mathrm{N}_{\mathrm{obs}}=21,670 ;\right. \\
\left.\mathrm{N}_{\mathrm{per}}=4,366\right)\end{array}$} \\
\hline & OR & CI & OR & CI & OR & CI & OR & CI & OR & CI \\
\hline z(age) & 0.58 & $0.51-0.67$ & 0.63 & $0.55-0.71$ & 0.62 & $0.55-0.7$ & 0.62 & $0.55-0.71$ & 0.62 & $0.55-0.70$ \\
\hline Sex (female) & 2.02 & $1.28-3.19$ & 1.88 & $1.25-2.83$ & 1.88 & $1.25-2.82$ & 1.88 & $1.25-2.83$ & 1.87 & $1.24-2.81$ \\
\hline Direct care & 1.56 & $1.29-1.88$ & 1.33 & $1.11-1.61$ & 1.42 & $1.18-1.71$ & 1.33 & $1.1-1.6$ & 1.38 & $1.15-1.66$ \\
\hline Nursing staff & 1.35 & $1.00-1.83$ & 1.09 & $0.84-1.43$ & 1.06 & $0.81-1.39$ & 1.09 & $0.83-1.43$ & 1.08 & $0.82-1.41$ \\
\hline PTE & - & - & 4.59 & $3.86-5.45$ & 4.81 & $4.06-5.71$ & 4.57 & $3.85-5.43$ & 4.61 & $3.88-5.47$ \\
\hline $\log (r+1)^{*}$ & - & - & - & - & 1.26 & $1.21-1.32$ & 1.21 & $1.02-1.43$ & 1.54 & $1.42-1.68$ \\
\hline z(time) & 2.65 & $2.31-3.03$ & 2.58 & $2.25-2.95$ & - & - & 1.62 & $1.06-2.49$ & 0.40 & $0.25-0.64$ \\
\hline $\mathrm{z}(\text { time })^{2}$ & 0.19 & $0.14-0.26$ & 0.20 & $0.14-0.27$ & - & - & 0.30 & $0.18-0.49$ & - & - \\
\hline $\mathrm{z}(\text { time })^{4}$ & 2.81 & $2.36-3.34$ & 2.61 & $2.19-3.10$ & - & - & 2.10 & $1.63-2.71$ & - & - \\
\hline $\mathrm{z}(\text { time })^{5}$ & 0.67 & $0.63-0.71$ & 0.70 & $0.66-0.74$ & - & - & 0.77 & $0.7-0.85$ & - & - \\
\hline $\log (\mathrm{r}+1) \times \mathrm{z}($ time $)$ & - & - & - & - & - & - & - & - & 1.10 & $1.03-1.18$ \\
\hline \multicolumn{11}{|l|}{ Random effect } \\
\hline$\sigma_{\mathrm{B}}$ & - & 17.39 & - & 10.72 & - & 10.28 & - & 10.81 & - & 10.42 \\
\hline
\end{tabular}

$\mathrm{OR}$ = odds ratio; $\mathrm{CI}=$ confidence interval; “-" = variable not in the model; Nobs = number of obser-vations, or personwaves, modeled; Nper = number of persons modeled); $\mathrm{z}($ time $)=$ Questionnaire answering time-variable standardized (z-score transformed) to mean 0 and variance $1 ; z(\text { time })^{k}=k^{\text {th }}$ polynomial of the time variable; $\sigma_{\mathrm{B}}=$ Random-effect variance for between-employee differences in risk of low mental health; $\mathrm{A} \times \mathrm{B}=$ interaction effect for A-by-B.

${ }^{*}$ Logarithm of weekly COVID-19 incidence, plus one case to prevent minus infinite log-values. 
Table 2: Multilevel models predicting sleep problems.

\begin{tabular}{|c|c|c|c|c|c|c|c|c|c|c|}
\hline \multirow[b]{2}{*}{ Fixed effects } & \multicolumn{2}{|c|}{$\begin{array}{c}\text { Model 1 } \\
\left(\mathrm{N}_{\text {obs }}=22,342 ;\right. \\
\left.\mathrm{N}_{\text {per }}=4,402\right)\end{array}$} & \multicolumn{2}{|c|}{$\begin{array}{c}\text { Model 2 } \\
\left(\mathrm{N}_{\text {obs }}=21,710 ;\right. \\
\left.\mathrm{N}_{\text {per }}=4,368\right)\end{array}$} & \multicolumn{2}{|c|}{$\begin{array}{c}\text { Model 3 } \\
\left(\mathrm{N}_{\text {obs }}=21,710 ;\right. \\
\left.\mathrm{N}_{\text {per }}=4,368\right)\end{array}$} & \multicolumn{2}{|c|}{$\begin{array}{c}\text { Model 4 } \\
\left(\mathrm{N}_{\text {obs }}=21,710 ;\right. \\
\left.\mathrm{N}_{\text {per }}=4,368\right)\end{array}$} & \multicolumn{2}{|c|}{$\begin{array}{c}\text { Model 5 } \\
\left(\mathrm{N}_{\text {obs }}=21,710 ;\right. \\
\left.\mathrm{N}_{\text {per }}=4,368\right)\end{array}$} \\
\hline & OR & CI & OR & CI & OR & CI & OR & CI & OR & CI \\
\hline z(age) & 0.84 & $0.69-1.03$ & 0.87 & $0.71-1.06$ & 0.86 & $0.7-1.05$ & 0.87 & $0.71-1.06$ & 0.86 & $0.71-1.05$ \\
\hline Sex (female) & 1.52 & $0.75-3.08$ & 1.45 & $0.72-2.93$ & 1.46 & $0.72-2.95$ & 1.45 & $0.72-2.93$ & 1.46 & $0.72-2.94$ \\
\hline Direct care & 1.66 & $1.28-2.16$ & 1.48 & $1.14-1.93$ & 1.62 & $1.25-2.1$ & 1.49 & $1.14-1.94$ & 1.59 & $1.22-2.07$ \\
\hline Nursing staff & 1.07 & $0.69-1.67$ & 0.99 & $0.64-1.54$ & 0.96 & $0.62-1.5$ & 0.99 & $0.64-1.54$ & 0.97 & $0.62-1.51$ \\
\hline PTE & - & - & 2.52 & $1.99-3.2$ & 2.71 & $2.14-3.42$ & 2.53 & $1.99-3.2$ & 2.63 & $2.07-3.32$ \\
\hline $\log (r+1)$ & - & - & - & - & 1.14 & $1.08-1.21$ & 0.88 & $0.7-1.1$ & 1.25 & $1.11-1.4$ \\
\hline z(time) & 1.97 & $1.64-2.36$ & 2.02 & $1.68-2.43$ & - & - & 2.81 & $1.55-5.08$ & 0.47 & $0.24-0.89$ \\
\hline $\mathrm{z}(\text { time })^{2}$ & 0.39 & $0.25-0.6$ & 0.36 & $0.23-0.57$ & - & - & 0.27 & $0.14-0.53$ & - & - \\
\hline $\mathrm{z}(\text { time })^{4}$ & 2.04 & $1.61-2.58$ & 2.05 & $1.61-2.61$ & - & - & 2.39 & $1.68-3.42$ & - & - \\
\hline $\mathrm{z}(\text { time })^{5}$ & 0.75 & $0.69-0.81$ & 0.75 & $0.69-0.81$ & - & - & 0.7 & $0.61-0.81$ & - & - \\
\hline $\begin{array}{l}\log (r+1) \times \\
\mathrm{z}(\text { time })\end{array}$ & - & - & - & - & - & - & - & - & 1.11 & $1.01-1.23$ \\
\hline \multicolumn{11}{|l|}{ Random effect } \\
\hline$\sigma_{\mathrm{B}}$ & - & 62.86 & - & 57.94 & - & 57.25 & - & 57.95 & - & 57.22 \\
\hline
\end{tabular}

$\mathrm{OR}$ = odds ratio; $\mathrm{CI}=$ confidence interval; “-" = variable not in the model; $\mathrm{N}_{\mathrm{obs}}=$ number of observations, or personwaves, modeled; $\mathrm{N}_{\text {per }}=$ number of persons modeled); $\mathrm{z}$ (time) = Questionnaire answering time-variable standardized (z-score transformed) to mean 0 and variance $1 ; \mathrm{z}(\text { time })^{k}=k^{\text {th }}$ polynomial of the time variable; $\sigma_{\mathrm{B}}=$ Random-effect variance for between-employee differences in risk of low mental health.

${ }^{*}$ Logarithm of weekly COVID-19 incidence, plus one case to prevent minus infinite log-values. 
Table 3: Multinomial regression coefficients from the class-membership part of a latentclass mixed model (see supplementary material for the entire model)

\begin{tabular}{|c|c|c|c|c|}
\hline \multirow[b]{2}{*}{ Fixed effects on class membership } & \multicolumn{2}{|c|}{ Class 1 (ref. Class 3) } & \multicolumn{2}{|c|}{ Class 2 (ref. Class 3) } \\
\hline & OR & Cl & OR & Cl \\
\hline PTE 1: work with Covid-19 patients shocking or burdening & 2.69 & $1.51-4.81$ & 12.79 & $7.02-23.33$ \\
\hline PTE 2: own or close one's risk of severe illness provoked severe anxiety & 16.96 & $7.12-40.42$ & 80.09 & $30.72-208.84$ \\
\hline PTE 3: self or close one hospitalized for Covid-19 infection & 2.33 & $0.86-6.28$ & 1.82 & $0.51-6.47$ \\
\hline PTE 4: relative or close one passed away due to Covid-19 infection & 0.39 & $0.06-2.38$ & 4.29 & $0.62-29.75$ \\
\hline Living alone & 1.87 & $1.34-2.62$ & 3.19 & $1.90-5.38$ \\
\hline
\end{tabular}

Note: Odds ratios (OR) are for class membership predictions, with 95\% Wald confidence intervals (CI) given in the adjacent columns. The reference class 3 ("stable mental health") was estimated to contain $62 \%$ ( $n=$ 2704) of employees in the available sample, whereas the class 1 ("early resilience, deteriorating") contained $24 \%(n=1040)$ and class 2 ("early shock, improving") contained 14\% ( $n=614)$ of employees. 


\section{Figures}

a)

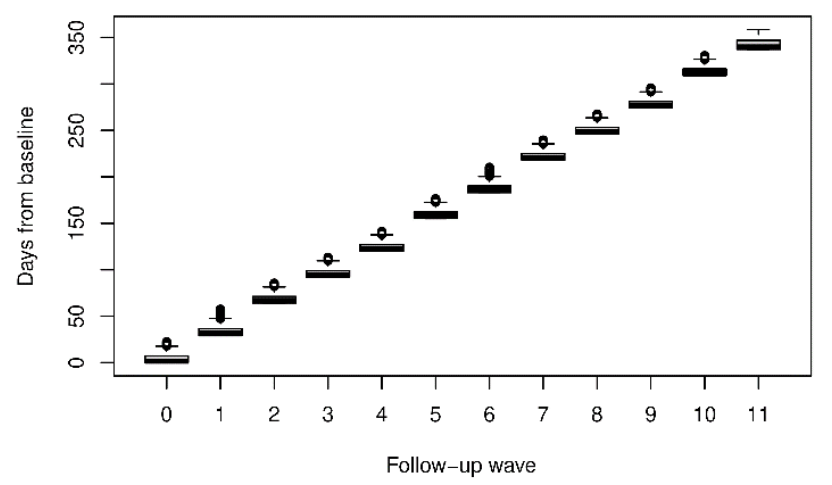

c)

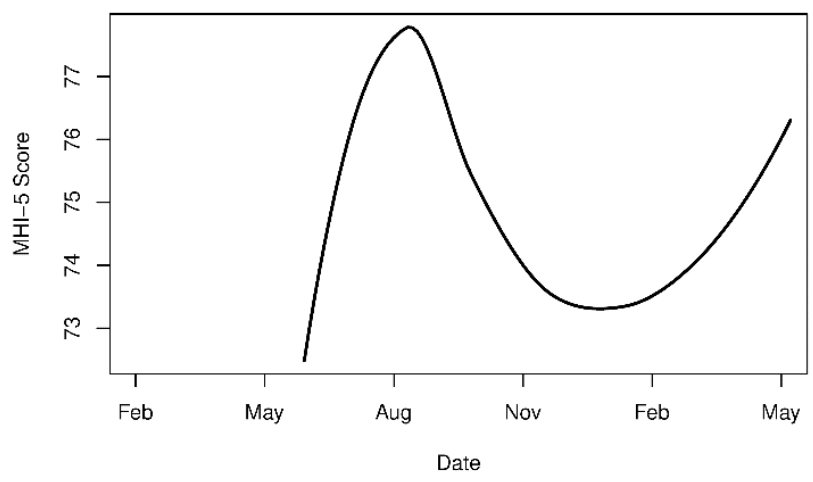

b)

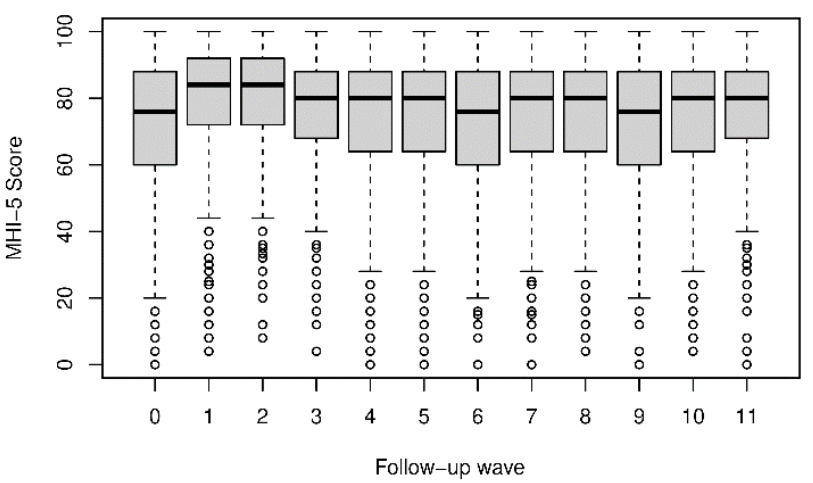

d)

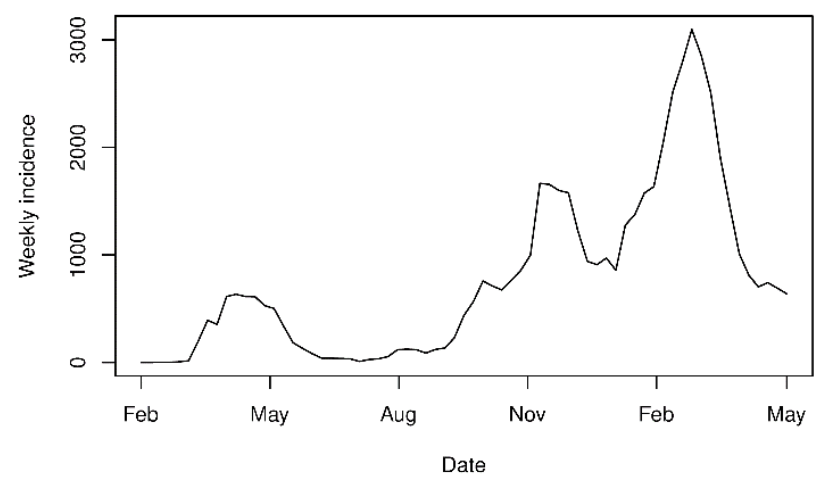

Figure 1. A 1-year monthly follow up of employee mental health plus local Covid-19 incidence. a) Boxplot of days since baseline by study wave. b) A 5-item Mental Health Index (MHI-5) by survey wave. c) Local regression of MHI-5 score on exact response date (note: these data start from June 2020). d) Weekly incidence of Covid-19 locally (in Uusimaa region, total population 1.7 million; note: these data are shown from beginning of the pandemic record up to our last survey response from the $12^{\text {th }}$ survey wave \#11). The incidence data are from the official open-access record by National Institute of Health and Welfare in Finland. 
a)

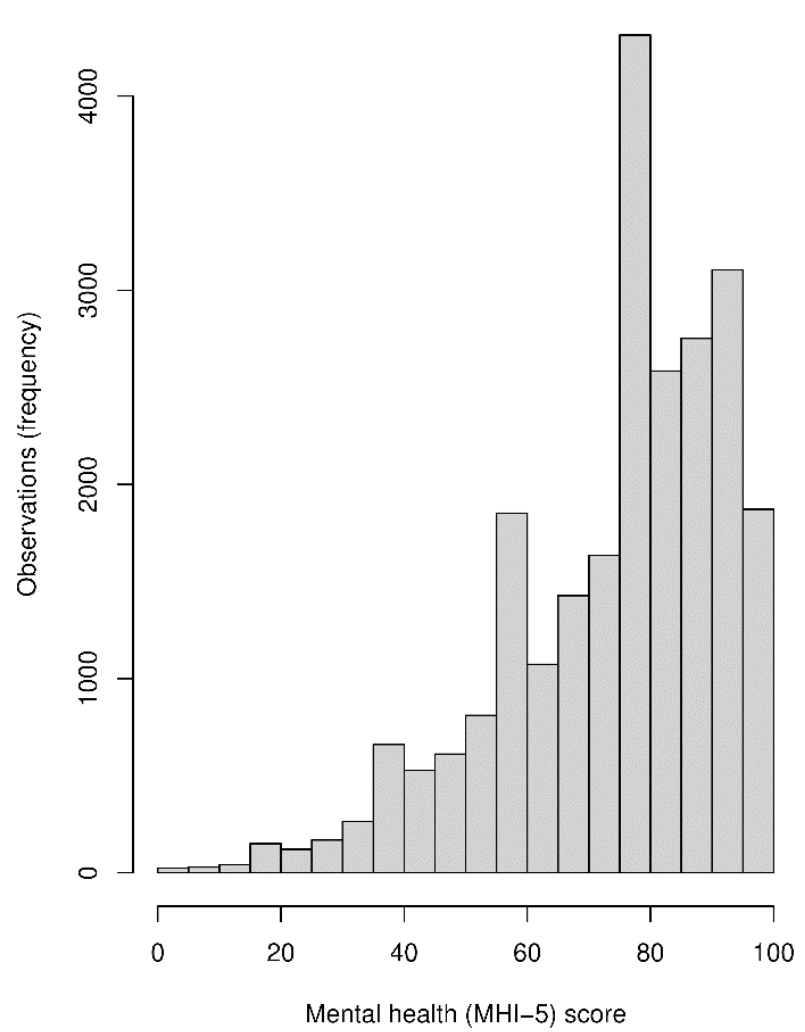

b)

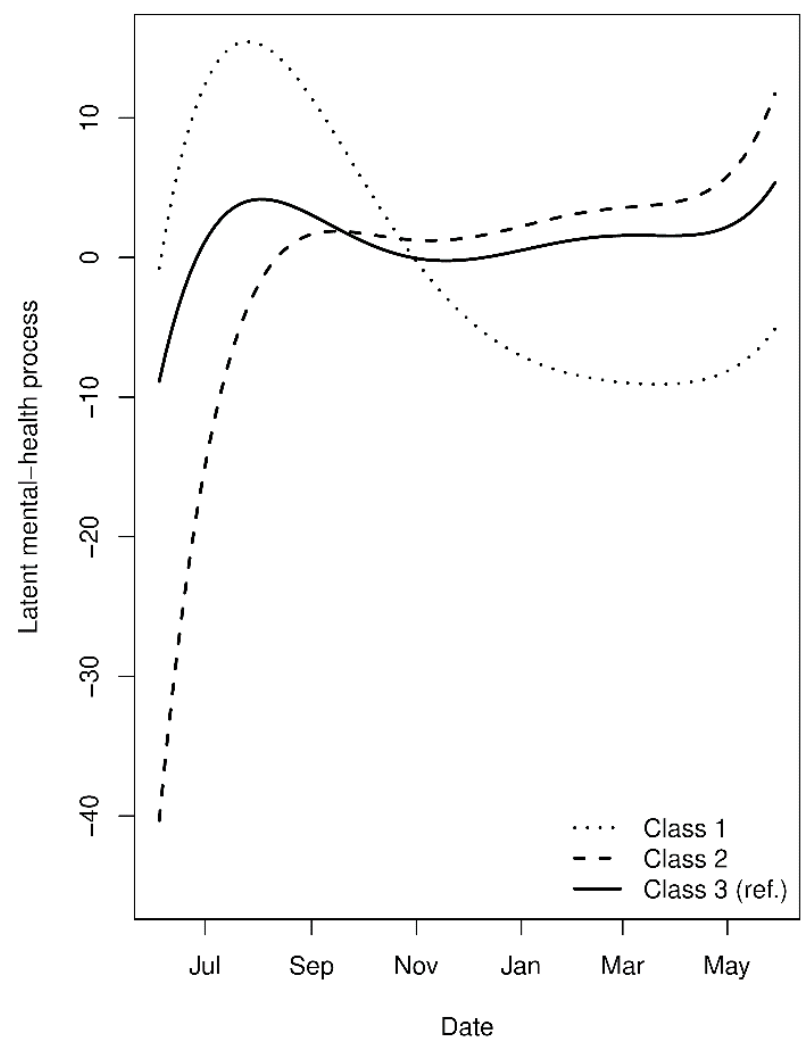

Figure 2. Latent class mixed modeling (lcmm). a) Distribution of observations of mental health (MHI-5) scores is supported strictly on interval from 0 to 100 and negatively skewed, suggesting re-scaled Beta distribution for the lcmm link function. b) Estimated latent trajectories from a 3-class lcmm model predicting MHI-5 scores with a degree 5 polynomial expansion of time, plus age and sex. The class memberships were further modeled with specific potentially traumatic events and living alone (Table 3; see supplementary material for a full set of numeric estimates). We named the latent classes "early resilience, deteriorating" (class 1), "early shock, improving" (class 2), and "stable mental health" (class 3, reference class). 


\title{
SUPPLEMENTARY MATERIAL:
}

\section{Healthcare workers' heterogeneous mental-health responses to prolonging Covid-19 pandemic: A full year of monthly follow up in Finland}

\begin{abstract}
Tom Rosenström, ${ }^{1,}{ }^{*}$ Katinka Tuisku, ${ }^{2}$ Jaana Suvisaari, ${ }^{3}$ Eero Pukkala, ${ }^{4}$ Kristiina Junttila, ${ }^{5}$ Henna Haravuori, ${ }^{3}$ Marko Elovainio,1,6 Toni Haapa,, Pekka Jylhä,, ${ }^{2}$ Tanja Laukkala²
\end{abstract}

${ }^{1}$ Department of Psychology and Logopedics, Faculty of Medicine, University of Helsinki, 00014 Helsinki, Finland

2 Department of Psychiatry, University of Helsinki and Acute Psychiatry and Consultations, HUS Helsinki University Hospital, 00029 Helsinki, Finland

${ }^{3}$ Finnish Institute for Health and Welfare, Mental Health Team, 00271 Helsinki, Finland

4 Faculty of Social Sciences, Tampere University, 33100 Tampere, Finland

5 Nursing Research Center, HUS Helsinki University Hospital and University of Helsinki, 00029 Helsinki, Finland

${ }^{6}$ Finnish Institute for Health and Welfare, Health Services Research, 00271 Helsinki, Finland

${ }^{*}$ Correspondence: tom.rosenstrom@helsinki.fi 
Table S1: Average sample characteristics by wave.

\begin{tabular}{|c|c|c|c|c|c|c|c|c|c|c|c|c|}
\hline \multirow[b]{2}{*}{ Variable } & \multicolumn{12}{|c|}{ Survey wave (waves 0-6 in year 2020, waves $7-11$ in year 2021) } \\
\hline & 0 & 1 & 2 & 3 & 4 & 5 & 6 & 7 & 8 & 9 & 10 & 11 \\
\hline $\begin{array}{l}\text { Date of } 1^{\text {st }} \\
\text { answer per wave } \\
\text { (mm:dd) }\end{array}$ & 06:04 & 07:03 & 08:07 & 09:04 & 10:02 & 11:06 & $12: 04$ & 01:08 & 02:05 & 03:05 & 04:09 & 05:07 \\
\hline $\mathrm{N}$ & 4804 & 2262 & 2172 & 1923 & 1913 & 1744 & 1685 & 1598 & 1579 & 1578 & 1523 & 1364 \\
\hline $\begin{array}{l}\text { At least } 1 \text { re- } \\
\text { participation (\%) } \\
\text { a }\end{array}$ & NA & 46.82 & 63.18 & 69.19 & 73.11 & 75.65 & 77.54 & 78.48 & 79.23 & 80.14 & 81.12 & 81.72 \\
\hline Woman (\%) ${ }^{\mathrm{b}}$ & 88.60 & 89.33 & 89.58 & 88.82 & 89.03 & 88.86 & 89.29 & 88.85 & 88.60 & 88.26 & 88.28 & 88.74 \\
\hline Age (years) & 46.74 & 49.55 & 48.50 & 48.18 & 48.89 & 48.31 & 49.54 & 47.68 & 47.78 & 49.63 & 48.08 & 47.86 \\
\hline Direct care (\%) ${ }^{c}$ & 24.40 & 14.32 & 14.19 & 14.19 & 16.83 & 16.76 & 20.27 & 19.35 & 19.30 & 20.11 & 19.47 & 18.43 \\
\hline $\begin{array}{l}\text { Nursing staff (\%) } \\
\mathrm{d}\end{array}$ & 63.03 & 62.30 & 61.02 & 59.85 & 59.64 & 60.71 & 61.54 & 58.99 & 58.87 & 58.69 & 58.80 & 60.18 \\
\hline $\begin{array}{l}\text { Work changes } \\
\text { (\%) }\end{array}$ & 82.37 & 39.48 & 29.31 & 37.05 & 40.20 & 23.04 & 38.97 & 20.72 & 18.01 & 29.88 & 24.81 & 17.13 \\
\hline MHI-5 (score) ${ }^{f}$ & 72.32 & 78.25 & 78.80 & 76.49 & 74.98 & 74.42 & 71.69 & 74.78 & 74.67 & 72.86 & 74.52 & 75.79 \\
\hline MHI- $5 \leq 52(\%)$ & 16.66 & 9.41 & 9.05 & 12.02 & 14.24 & 15.02 & 19.14 & 13.59 & 14.25 & 17.06 & 13.52 & 13.45 \\
\hline ISI (score) g & 7.11 & 6.33 & 6.05 & 6.35 & 6.60 & 6.61 & 6.95 & 6.86 & 6.52 & 6.64 & 6.59 & 6.42 \\
\hline ISI $\geq 15(\%)$ & 9.53 & 5.88 & 5.57 & 7.54 & 7.58 & 7.51 & 8.78 & 8.76 & 8.23 & 8.43 & 8.40 & 7.55 \\
\hline PTE (\%) ${ }^{\mathrm{h}}$ & 27.85 & 18.60 & 15.89 & 13.23 & 13.61 & 12.81 & 17.18 & 14.95 & 11.76 & 15.99 & 14.84 & 13.24 \\
\hline PTE1 (\%) ${ }^{\mathrm{i}}$ & 12.99 & 8.28 & 6.26 & 5.21 & 4.74 & 4.41 & 6.38 & 5.00 & 3.68 & 6.32 & 5.87 & 5.03 \\
\hline PTE2 (\%) ${ }^{j}$ & 19.87 & 12.00 & 9.74 & 8.35 & 8.76 & 7.74 & 11.74 & 9.63 & 7.43 & 9.63 & 7.25 & 5.92 \\
\hline PTE3 (\%) k & 2.84 & 2.92 & 3.37 & 2.57 & 2.81 & 3.03 & 3.31 & 3.56 & 3.51 & 4.36 & 4.77 & 4.80 \\
\hline PTE4 (\%) ${ }^{1}$ & 0.83 & 1.12 & 1.12 & 1.00 & 1.11 & 0.87 & 0.84 & 1.40 & 1.21 & 1.86 & 1.49 & 1.50 \\
\hline
\end{tabular}

${ }^{a}$ At least one re-participation to surveys after the zero survey wave.

b Woman or someone not indentifying as man.

c Directly caring for COVID-19 patients.

$\mathrm{d}$ Belonging to nursing staff at baseline (i.e., in survey wave 0 ).

e Reporting changes in work due to COVID-19.

${ }^{f}$ MHI-5 (Mental Health Index -5 rating, 0-100 points under 53 refer to psychological distress).

$\mathrm{g}$ ISI (Insomnia severity index rating $0-28$ points, 15 or over refer to moderate or severe insomnia symptoms).

h Potentially traumatic event (any of PTE 1-4, questions i-l below).

${ }^{i}$ Has your work with suspected or confirmed COVID-19 patients included exceptionally disturbing or distressing assignments?

j Have you had strong anxiety due to your own or close one's risk of contracting serious illness for your work with suspected or confirmed COVID-19 patients?

k Have you or your close one contracted a severe COVID-19 that required hospital care?

${ }^{1}$ Has a close one to you died of COVID-19? 
Table S2. Logistic regression mixed model predicting low mental health ( $\mathrm{MHI}-5 \leq 52$ ) in 21587 observations from 4346 individuals ( $\mathrm{OR}=$ odds ratio; $\mathrm{Cl}=95 \%$ confidence interval).

\begin{tabular}{|c|c|c|}
\hline Fixed effects & $\mathbf{O R}$ & CI \\
\hline z(age) & 0.64 & $0.56-0.72$ \\
\hline Woman & 1.88 & $1.25-2.82$ \\
\hline Direct care & 1.34 & $1.11-1.61$ \\
\hline Nurse & 1.10 & $0.84-1.44$ \\
\hline PTE & 4.36 & $3.67-5.19$ \\
\hline Living alone & 2.51 & $1.86-3.38$ \\
\hline $\mathrm{z}$ (time) & 2.90 & $2.50-3.36$ \\
\hline$z(\text { time })^{2}$ & 0.19 & $0.14-0.27$ \\
\hline $\mathrm{z}(\text { time })^{4}$ & 2.58 & $2.17-3.07$ \\
\hline$z(\text { time })^{5}$ & 0.70 & $0.66-0.75$ \\
\hline $\mathrm{PTE}^{*} \mathrm{z}$ (time) & 0.69 & $0.60-0.79$ \\
\hline Living alone ${ }^{*} \mathrm{z}$ (time) & 0.94 & $0.82-1.07$ \\
\hline \multicolumn{3}{|l|}{ Random effect } \\
\hline$\sigma_{\mathrm{B}}$ & - & 10.33 \\
\hline
\end{tabular}




\section{Selection of the latent class mixed model}

From previous analysis, we knew approximately $5^{\text {th }}$ degree polynomial expansion to be a fitting description of effects of time on the risk of low mental health. This was verified in the latent class mixed model predicting MHI-5 scores through a re-scaled Beta link and just one latent class: relative Bayesian information criteria $(\Delta B I C)$ for $4^{\text {th }}, 5^{\text {th }}$, and $6^{\text {th }}$ order expansions being $84.7,0.0$, 5.8, respectively. We then examined relative BIC values for different numbers of latent classes, each having a distinct $5^{\text {th }}$ degree polynomial expansion for time-effects on MHI-5 scores. While absolute BIC minimum appeared elusive, the most dramatic drop in value was over after including three latent classes (see below figure). For large numbers of classes, the class members would begin having a relative high posterior probability of belonging to some other class; in other words, decline in class interpretability might exceed gains in total information when going beyond three classes. Indeed, the three-class solution had the best entropy (classification-based) criterion and the best integrated classification likelihood (ICL) criterion, which combines BIC with a measure of entropy (Table S3). Therefore, we further interpreted a model with three latent classes. 


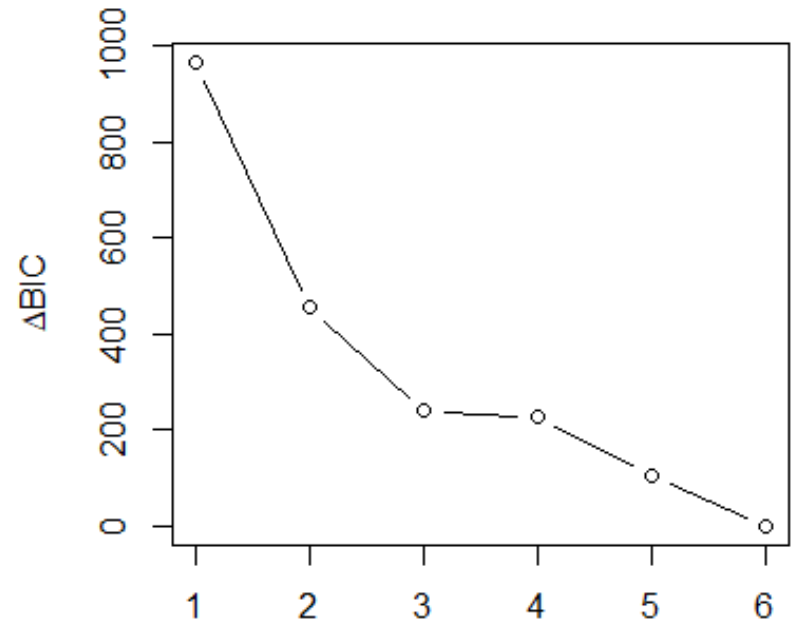

Number of latent classes

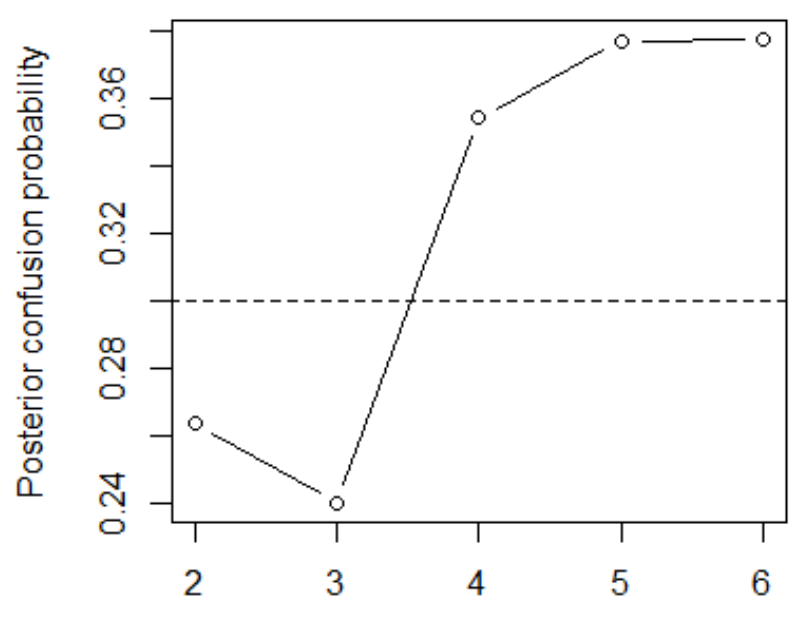

Number of latent classes

\section{Table S3. Latent-class mixture model-selection summary table.}

\begin{tabular}{cccccccc}
\hline $\begin{array}{c}\text { Number } \\
\text { of latent } \\
\text { classes }\end{array}$ & $\begin{array}{c}\text { Log- } \\
\text { likelihood }\end{array}$ & $\begin{array}{c}\text { Number of } \\
\text { parameters }\end{array}$ & $\begin{array}{c}\text { AIC } \\
\text { plC }\end{array}$ & $\begin{array}{c}\text { SABIC } \\
\text { BItropy }\end{array}$ & ICL \\
1 & -84854.39 & 12 & 169732.78 & 169809.50 & 169771.37 & 1.00 & 169809.50 \\
2 & -84569.24 & 19 & 169176.48 & 169297.95 & 169237.58 & 0.28 & 162765.42 \\
3 & -84432.28 & 26 & 168916.57 & 169082.80 & 169000.18 & $0.61^{*}$ & $161736.80^{*}$ \\
4 & -84396.47 & 33 & 168858.95 & 169069.94 & 168965.08 & 0.49 & 162729.16 \\
5 & -84306.68 & 40 & 168693.36 & 168949.11 & 168822.01 & 0.51 & 162933.30 \\
6 & $-84224.67^{*}$ & 47 & $168543.33^{*}$ & $168843.83^{*}$ & $168694.49^{*}$ & 0.57 & 162555.21 \\
\hline
\end{tabular}

Note: Stars ( $\left.{ }^{*}\right)$ in superscript indicate model favored by the criterion of the column. Lower values are better for Akaike Information Criterion (AIC), Bayesian Information Criterion (BIC), Sample-size Adjusted BIC (SABIC), and Integrated Completed Likelihood (ICL). Higher values are better for log-likelihood and entropy, but entropy is trivially 1 for single-class models. 
Table S4. Breakdown of variables by survey wave and predicted latent class

\begin{tabular}{|c|c|c|c|c|c|c|c|c|}
\hline Wave & Class & PTE (\%) & PTE1 (\%) & PTE2 (\%) & PTE3 (\%) & PTE4 (\%) & Alone (\%) & N \\
\hline \multirow[t]{3}{*}{0} & 1 & 44.72 & 13.25 & 33.56 & 4.79 & 0.29 & 29.62 & 1040 \\
\hline & 2 & 92.12 & 54.02 & 79.18 & 4.59 & 2.46 & 33.71 & 614 \\
\hline & 3 & 6.14 & 3.51 & 0.75 & 1.72 & 0.64 & 17.38 & 2704 \\
\hline \multirow[t]{3}{*}{1} & 1 & 22.29 & 6.74 & 14.51 & 4.02 & 0.77 & 30.81 & 529 \\
\hline & 2 & 57.82 & 31.74 & 42.32 & 7.17 & 3.41 & 32.78 & 299 \\
\hline & 3 & 7.30 & 3.34 & 3.34 & 1.50 & 0.71 & 17.57 & 1286 \\
\hline \multirow[t]{3}{*}{2} & 1 & 21.43 & 7.08 & 13.57 & 4.38 & 1.03 & 29.04 & 489 \\
\hline & 2 & 47.17 & 23.97 & 34.21 & 7.46 & 2.25 & 30.15 & 272 \\
\hline & 3 & 6.70 & 2.36 & 2.27 & 2.26 & 0.81 & 17.29 & 1255 \\
\hline \multirow[t]{3}{*}{3} & 1 & 19.11 & 5.75 & 13.02 & 4.15 & 0.88 & 27.39 & 460 \\
\hline & 2 & 37.56 & 18.72 & 28.77 & 4.48 & 2.24 & 32.30 & 226 \\
\hline & 3 & 5.87 & 2.23 & 2.32 & 1.57 & 0.83 & 16.97 & 1096 \\
\hline \multirow[t]{3}{*}{4} & 1 & 19.95 & 6.32 & 13.82 & 3.70 & 0.92 & 27.44 & 441 \\
\hline & 2 & 41.41 & 16.67 & 31.72 & 6.58 & 2.19 & 29.87 & 231 \\
\hline & 3 & 5.34 & 1.68 & 1.96 & 1.66 & 0.92 & 17.06 & 1102 \\
\hline \multirow[t]{3}{*}{5} & 1 & 17.19 & 5.17 & 11.83 & 3.85 & 0.78 & 26.08 & 395 \\
\hline & 2 & 35.78 & 14.81 & 26.48 & 4.57 & 1.83 & 34.70 & 219 \\
\hline & 3 & 5.82 & 2.13 & 1.53 & 2.42 & 0.80 & 15.74 & 1010 \\
\hline \multirow[t]{3}{*}{6} & 1 & 27.76 & 7.82 & 20.05 & 4.41 & 0.49 & 27.64 & 416 \\
\hline & 2 & 45.27 & 23.5 & 35.82 & 5.47 & 2.49 & 29.56 & 203 \\
\hline & 3 & 6.53 & 2.28 & 2.80 & 2.47 & 0.64 & 15.73 & 947 \\
\hline \multirow[t]{3}{*}{7} & 1 & 23.82 & 5.79 & 17.13 & 5.75 & 1.09 & 27.96 & 372 \\
\hline & 2 & 38.22 & 18.32 & 29.32 & 5.73 & 3.12 & 34.69 & 196 \\
\hline & 3 & 6.55 & 2.36 & 2.47 & 2.22 & 1.23 & 16.68 & 911 \\
\hline \multirow[t]{3}{*}{8} & 1 & 21.2 & 6.56 & 15.14 & 4.95 & 1.83 & 29.09 & 385 \\
\hline & 2 & 32.54 & 13.02 & 21.89 & 7.10 & 3.55 & 36.84 & 171 \\
\hline & 3 & 3.82 & 0.90 & 1.35 & 1.99 & 0.55 & 16.76 & 913 \\
\hline \multirow[t]{3}{*}{9} & 1 & 23.75 & 9.52 & 15.57 & 6.51 & 1.56 & 27.51 & 389 \\
\hline & 2 & 43.62 & 19.15 & 31.22 & 8.47 & 6.32 & 35.08 & 191 \\
\hline & 3 & 6.98 & 2.67 & 2.43 & 2.62 & 1.02 & 17.00 & 888 \\
\hline \multirow[t]{3}{*}{10} & 1 & 22.32 & 8.36 & 13.04 & 5.16 & 1.43 & 27.86 & 359 \\
\hline & 2 & 35.93 & 17.16 & 23.08 & 8.98 & 5.33 & 33.53 & 173 \\
\hline & 3 & 7.11 & 2.20 & 1.22 & 3.70 & 0.83 & 17.63 & 868 \\
\hline \multirow[t]{3}{*}{11} & 1 & 18.71 & 6.75 & 10.33 & 5.45 & 1.22 & 24.56 & 338 \\
\hline & 2 & 35.98 & 18.29 & 20.00 & 8.43 & 3.61 & 34.71 & 170 \\
\hline & 3 & 6.57 & 1.50 & 1.22 & 4.01 & 1.20 & 15.82 & 765 \\
\hline
\end{tabular}

Note: Across all the waves, the latent classes 1, 2, and 3 contained $25.9 \%, 52.5 \%$, and $6.2 \%$ of employees who had potentially traumatic events (PTE), respectively, and $28.2 \%, 33.0 \%$, and $16.9 \%$ of employees who lived alone. Alone refers to living alone (not cohabiting) and the PTEs 1-4 correspond to Table 3 in main text: "work with Covid-19 patients shocking or burdening"; "own or close one's risk of severe illness provoked 
severe anxiety"; "self or close one hospitalized for Covid-19 infection"; and "relative or close one passed away due to Covid-19 infection". Predicted class memberships per individual are point estimates subject to uncertainty. Refer to Table 3 in main text regarding uncertainty estimates. 


\section{A summary of the latent class mixed model}

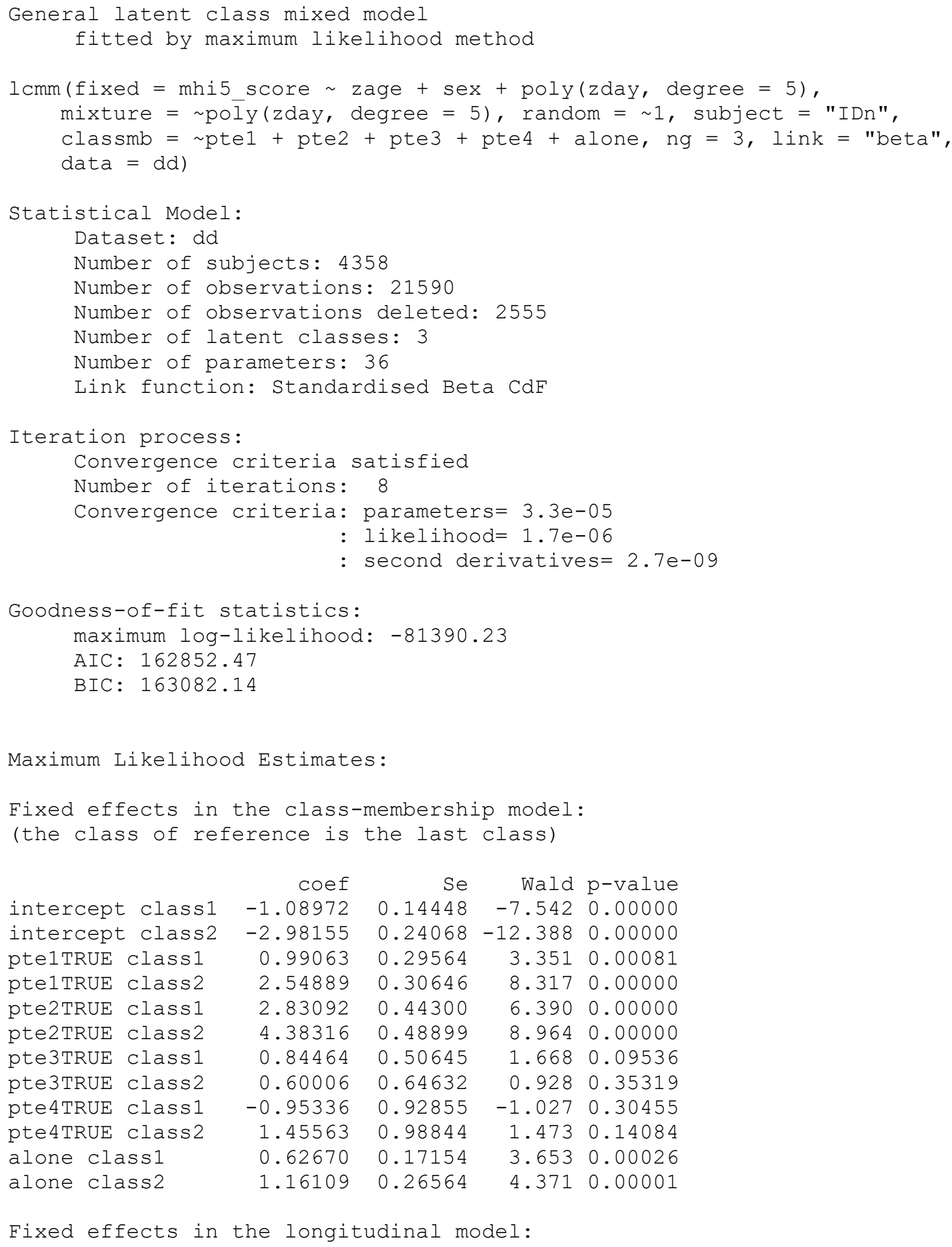




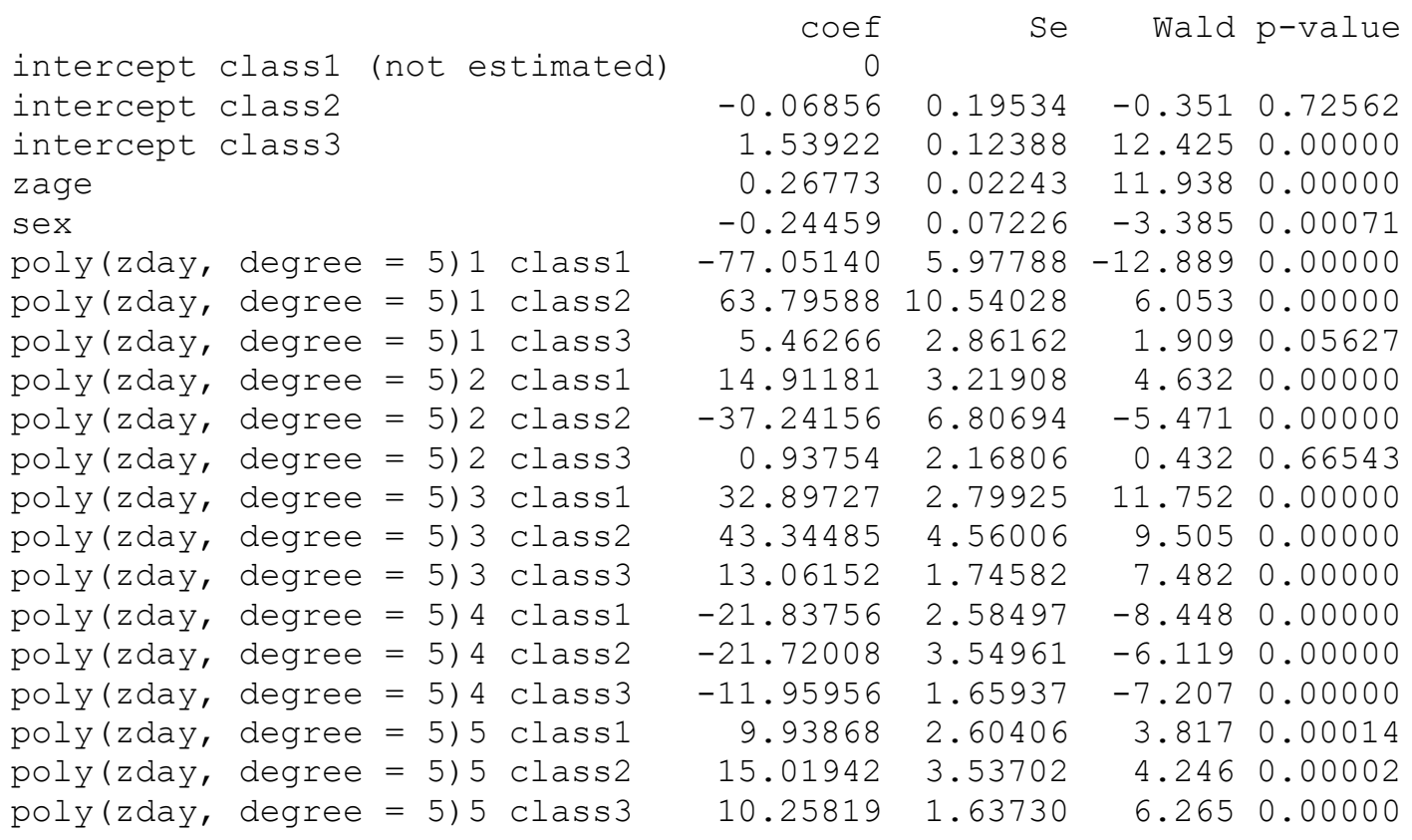

Variance-covariance matrix of the random-effects: intercept

intercept $\quad 1.56669$

Residual standard error (not estimated) $=1$

Parameters of the link function:

$\begin{array}{lrrrr} & \text { coef } & \text { Se } & \text { Wald } & \text { p-value } \\ \text { Beta1 } & 0.58579 & 0.02491 & 23.517 & 0.00000 \\ \text { Beta2 } & -0.22215 & 0.02875 & -7.728 & 0.00000 \\ \text { Beta3 } & 0.48385 & 0.01093 & 44.275 & 0.00000 \\ \text { Beta4 } & 0.08703 & 0.00131 & 66.398 & 0.00000\end{array}$

